Cite this: Polym. Chem., 2013, 4, 5537

\section{Ferrocene-based poly(aroxycarbonyltriazole)s: synthesis by metal-free click polymerization and use as precursors to magnetic ceramics $\dagger$}

Received 8th July 2013

Accepted 27th July 2013

DOI: $10.1039 /$ c3py00892d

www.rsc.org/polymers

Ferrocene-based poly(aroxycarbonyltriazole)s with high molecular weights and regioregularities were prepared in high yields by the efficient metal-free click polymerization of dipropiolates and the ferrocene-containing diazide under mild reaction conditions. The resulting polytriazoles are redox active, and could be used as precursors to generate soft magnetic ceramics with high magnetizability and low coercivity when pyrolyzed at elevated temperatures.

Organometallic polymers, with advantages of both the organic and metallic components, have drawn much attention in the past decades due to their unique electrical, magnetic, optical, sensing and catalytic properties. ${ }^{1}$ They are potentially applicable as catalysts, biomedical materials, precursor-derived ceramics and in electrode modifiers, nonlinear optical devices, electrochemical sensors, etc. Among the organometallic polymers, ferrocenebased ones have been widely investigated because they possess unique redox properties and structure variation. ${ }^{2}$ There are many polymerization reactions used to prepare the ferrocene-based linear and branched polymers. ${ }^{3}$ For example, Manners and

${ }^{a}$ MOE Key Laboratory of Macromolecular Synthesis and Functionalization, Department of Polymer Science and Engineering, Zhejiang University, Hangzhou, 310027, China. E-mail: qinaj@zju.edu.cn; tangbenz@ust.hk; Fax: +86-57187953734; Tel: +86-571-87953734

${ }^{b}$ Department of Chemistry, Institute for Advanced Study, Institute of Molecular Functional Materials, The Hong Kong University of Science \& Technology, Clear Water Bay, Kowloon, Hong Kong, China

${ }^{c}$ Guangdong Innovative Research Team, State Key Laboratory of Luminescent Materials and Devices, South China University of Technology, Guangzhou 510640, China

$\dagger$ Electronic supplementary information (ESI) available: Experimental section, synthetic route to the diazide monomer 2 (Scheme S1), FTIR and ${ }^{13} \mathrm{C}$ NMR spectra of P3a and its monomers (Fig. S1 and S2), FTIR, ${ }^{1} \mathrm{H}$ and ${ }^{13} \mathrm{C}$ NMR spectra of P3b and P3c and their monomers (Fig. S3-S8), TGA and DSC thermograms of P3 (Fig. S9 and S10, respectively), HRTEM images of C3a, C3b and C3c (Fig. S11), XRD patterns of P3 (Fig. S12), electrochemical data of P3 (Table S1), and compositions of C3a, C3b and C3c (Table S2). See DOI: 10.1039/c3py00892d coworkers have prepared soluble linear poly(ferrocenylsilane)s with high molecular weights by thermally induced, transition metal-catalyzed, anionic and photolytic ring-opening polymerization reactions of silaferrocenophanes. ${ }^{4}$ We have used the polycyclotrimerization of ferrocene-containing alkynes to synthesize ferrocene-functionalized hyperbranched polymers with redox activities and soft magnetic properties. ${ }^{5}$ Most of these polymerization reactions, however, must be performed under harsh reaction conditions, which normally require careful exclusion of moisture and oxygen, and greatly limit their further applications. The development of facile synthetic approaches to prepare ferrocene-containing polymers is, thus, still highly desired.

The robust and orthogonal azide-alkyne click polymerization, ${ }^{6}$ which was developed based on the well-established click reactions, ${ }^{7}$ will be an ideal alternative for the preparation of such polymers. Barner-Kowollik and coworkers have prepared ferrocene-containing polytriazoles with high molecular weights by employing the $\mathrm{Cu}(\mathrm{I})$-catalyzed azide-alkyne click polymerization. ${ }^{3 d}$ Although ferrocene-based polytriazoles may be used for biomedical applications, the copper residues in the polymers could cause cytotoxicity; the complete removal of them after polymerization is, however, difficult. ${ }^{8}$ One way to surmount this difficulty and to enable the ferrocene-based polymers to be applied in biological fields is to develop a click polymerization reaction without using transition metal catalysts, i.e. metal-free click polymerization. ${ }^{\mathbf{6 a b}}$

During the course of exploration of new alkyne-based polymerization reactions, ${ }^{9}$ we found that the carbonyl/ester groupactivated alkynes, i.e. aroylacetylenes and propiolates, and perfluorobenzophenone-activated azides could react with their azides and alkynes comonomers under mild reaction conditions in the absence of $\mathrm{Cu}(\mathrm{I})$ catalysts, respectively. ${ }^{\mathbf{1 0}}$ For example, dipropiolates and diazides could be facilely polymerized at $100{ }^{\circ} \mathrm{C}$ for $24 \mathrm{~h}$ in polar solvents such as DMF/toluene and soluble poly(aroxycarbonyltriazole)s (PACTs) with high molecular weights ( $M_{\mathrm{w}}$ up to 23500$)$ and regioregularities [the fraction of 1,4-disubstituted 1,2,3-triazoles $\left(F_{1,4}\right)$ is up to $90 \%$ ] were obtained in excellent yields (up to 99\%). Since these reactions meet the requirements of click chemistry defined by 
Sharpless and coworkers in $2001,{ }^{11}$ they could be regarded as click reactions. In other words, we have succeeded in establishing a new type of metal-free click polymerization (MFCP). As no copper catalyst was used, the produced polymers are less toxic and their optoelectronic properties could be retained, which may allow them to find broad applications in biological and optoelectronic fields.

With such a powerful polymerization method in hand, we are interested in expanding its application and preparing linear and hyperbranched polymers with advanced functional properties. In this paper, we applied the propiolate-azide MFCP to synthesize a group of linear ferrocene-based PACTs.

The dipropiolate monomers (1) were synthesized following our previously reported procedures. ${ }^{10 e}$ The ferrocene-containing diazide, 1,1'-bis(azidomethyl)ferrocene (2), was prepared from ferrocene according to previously published procedures [Scheme S1, ESI $\dagger]^{3 d}$ The reactions proceeded smoothly and the desired products were obtained in satisfactory yields (the detailed synthesis and characterization data are included in the ESI $\dagger$ ).

The synthetic routes to ferrocene-based PACTs are shown in Scheme 1 . We first tried to polymerize $1 \mathrm{a}$ and 2 in DMF at $100{ }^{\circ} \mathrm{C}$ for $24 \mathrm{~h}$, which are our reported optimized reaction conditions. ${ }^{10 e}$ Unfortunately, only insoluble black products with low molar mass were obtained, which may be due to some of $1,1^{\prime}$ bis(azidomethyl)ferrocene monomer having decomposed at this temperature. We then reduced the temperature to $80{ }^{\circ} \mathrm{C}$. Delightfully, the polymerization of $1 \mathrm{a}$ and $\mathbf{2}$ could produce the soluble polymer P3a with high $M_{\mathrm{w}}(13400)$ and narrow PDI (1.51) in a high yield $(94.5 \%$, no. 1 in Table 1$)$. Thus, we employed the same reaction conditions to polymerize aliphatic dipropiolates $\mathbf{1 b}$ and $\mathbf{1 c}$ with diazide 2 . Both of the polymerization reactions propagated smoothly and produced $\mathbf{P} 3 \mathbf{b}$ and P3c with similar results to those of P3a (no. 2 and 3 in Table 1). It is worth noting that the click polymerization could also be performed in air without protection from oxygen and moisture (no. 4 in Table 1), and no negative effect was observed, which

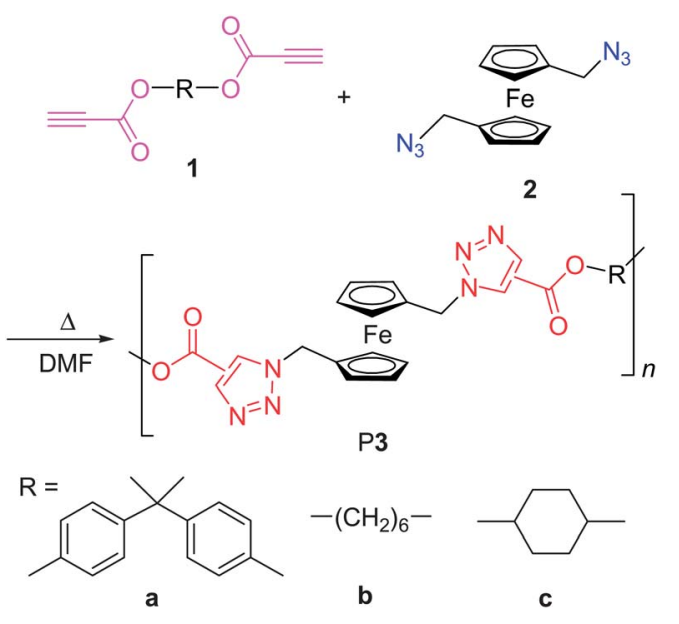

Scheme 1 Synthesis of ferrocene-based poly(aroxycarbonyltriazole)s (PACTs) P3a, P3b and P3c by metal-free click polymerization reactions of dipropiolates $\mathbf{1}$ and diazide 2.
Table 1 Click polymerization reactions of dipropiolates $\mathbf{1}$ and diazide $\mathbf{2}^{a}$

\begin{tabular}{lllllll}
\hline No. & Polymer & Monomers & Yield $(\%)$ & $M_{\mathrm{W}}{ }^{b}$ & PDI $^{b}$ & $F_{1,4}{ }^{c}(\%)$ \\
\hline $\mathbf{1}$ & P3a & $\mathbf{1 a}+\mathbf{2}$ & 94.5 & 13400 & 1.51 & 92.6 \\
2 & P3b & $\mathbf{1 b}+\mathbf{2}$ & 95.9 & 12700 & 1.54 & 88.5 \\
3 & P3c & $\mathbf{1 c}+\mathbf{2}$ & 96.9 & 12700 & 1.59 & 87.7 \\
4 & P3a $^{d}$ & $\mathbf{1 a}+\mathbf{2}$ & 92.7 & 12100 & 1.49 & 91.7
\end{tabular}

${ }^{a}$ Carried out in DMF at $80{ }^{\circ} \mathrm{C}$ under nitrogen for $24 \mathrm{~h}$ with $[1]=[2]=$ $0.167 \mathrm{M} .{ }^{b}$ The relative weight-average molecular weights $\left(M_{\mathrm{w}}\right)$ of the polymers and their polydispersity indices (PDI, $M_{\mathrm{w}} / M_{\mathrm{n}}$ ) estimated by GPC in DMF containing $0.05 \mathrm{M} \mathrm{LiBr}$ on the basis of a set of monodisperse poly(methyl methacrylate) calibrations. ${ }^{c}$ The fraction of the 1,4-regioisomer calculated from ${ }^{1} \mathrm{H}$ NMR spectra of the polymers. ${ }^{d}$ Carried out in an open atmosphere.

will simplify the polymerization process. The resulting polytriazoles are completely soluble in polar solvents, such as DMF and DMSO, but partially soluble in chloroform and THF.

The structures of PACTs were characterized by spectroscopic techniques and satisfactory results were obtained (see the ESI $\dagger$ for details). The ${ }^{1} \mathrm{H}$ NMR spectra of P3a and its monomers 1a and 2 are shown in Fig. 1. All the resonance peaks of the polymer and monomers are readily assignable. The resonances of ethynyl protons of 1a and the methylene protons adjacent to the azido group of 2 are located at $\delta 4.84$ and 4.29, respectively, which almost disappeared in the spectrum of P3a. In addition, four new resonance peaks are observed at $\delta 8.98,8.50,5.69$ and
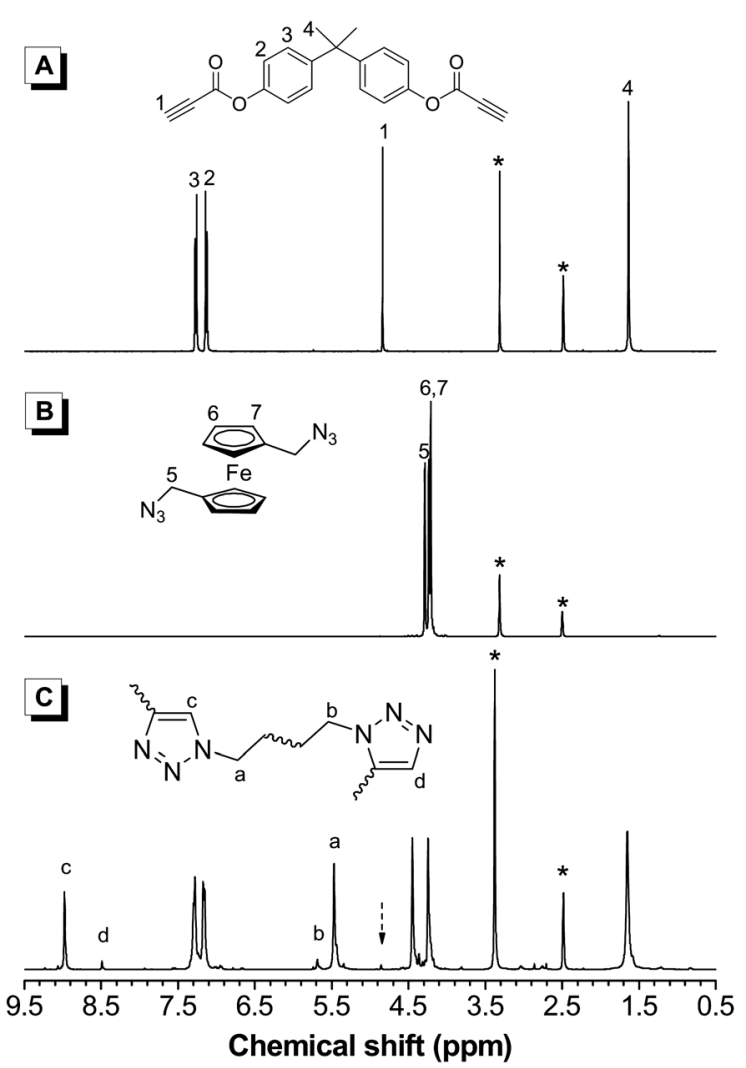

Fig. $1{ }^{1}$ H NMR spectra of monomers $\mathbf{1 a}(A)$ and $\mathbf{2}(B)$ and the polymer $\mathrm{P} 3 \mathbf{a}(\mathrm{C})$ in DMSO- $d_{6}$. The solvent and water peaks are marked with asterisks. 
5.47. According to our previous reports, the intense peaks at $\delta$ 8.98 and 5.47 are associated with the resonances of the protons in triazole rings (c) and their neighboring methylene groups (a) of the 1,4-isomeric units, whereas, the weak signals at $\delta 8.50$ (d) and 5.69 (b) are stemmed from those in 1,5-isomeric units. ${ }^{10 c, e}$ These results indicate that most of the alkyne and azido groups of the monomers have been transformed into the triazole rings of the PACTs by the click polymerization. The IR and ${ }^{13} \mathrm{C}$ NMR spectra (Fig. S1 and S2, ESI $\dagger$ ) of P3a and its monomers further substantiate the conclusions drawn from the ${ }^{1} \mathrm{H}$ NMR spectra.

Furthermore, the resonance peaks at $\delta 8.98$ and 8.50 are well separated in the spectrum of P3a (Fig. 1C), which enables us to utilize their integrals to calculate the fraction of the 1,4-disubstituted 1,2,3-triazole unit $\left(F_{1,4}\right)$ in the polymer. The value is calculated to be as high as $92.6 \%$. The IR, ${ }^{1} \mathrm{H}$ and ${ }^{13} \mathrm{C}$ NMR (Fig. S3-S8, ESI $\dagger$ ) spectral profiles of P3b and P3c are similar to those of P3a. Moreover, P3b and P3c also have high $F_{1,4}$ values (Table 1). These results confirm that the metal-free click polymerization is indeed a powerful synthetic tool for the preparation of ferrocene-based polytriazoles.

The thermal stabilities of the polymers were evaluated by thermogravimetric analysis (TGA) and differential scanning calorimetry (DSC). The results of the TGA show that the polymers lose $5 \%$ of their weights at temperatures higher than $295{ }^{\circ} \mathrm{C}$ under nitrogen (Fig. S9, ESI $\dagger$ ), suggesting that the polymers are thermally stable. The glass transition temperatures $\left(T_{\mathrm{g}}\right)$ of P3a and P3c are higher than $150{ }^{\circ} \mathrm{C}$, but that of P3b is only $78.4{ }^{\circ} \mathrm{C}$ as it contains flexible alkyl chains (Fig. S10, ESI $\dagger$ ).

The PACTs are electrochemically active as they contain ferrocene units. Their redox behaviors were investigated by cyclic voltammetry (CV) in dichloromethane (DCM) solutions. The CV curves display similar patterns in Fig. 2 and the electrochemical data of the polymers are summarized in Table S1 (ESI $\dagger$ ). All the PACTs exhibit a single oxidation peak in the range of 0 to $1.5 \mathrm{~V}$

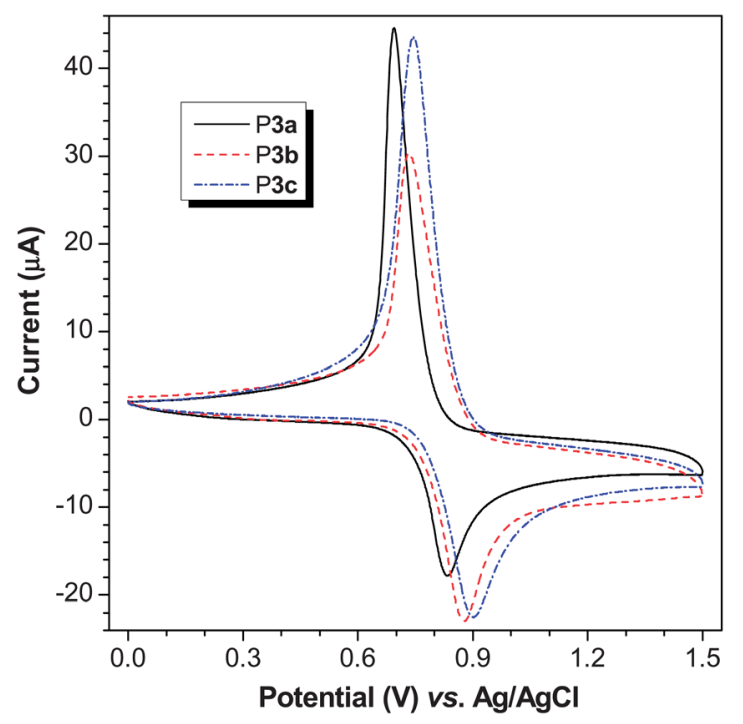

Fig. 2 Cyclic voltammograms of P3a, P3b and P3c in DCM containing $0.1 \mathrm{M}[(n-$ $\mathrm{Bu})_{4} \mathrm{~N}_{\mathrm{PF}}$. Scan rate: $100 \mathrm{mV} \mathrm{s}^{-1}$. Concentration $\left(\mathrm{mg} \mathrm{mL}^{-1}\right)$ : P3a: 0.93, P3b: 1.07, P3c: 0.95 . (vs. $\mathrm{Ag} / \mathrm{AgCl}$ ), which is similar to that of ferrocene. The half-wave potentials $\left(E_{1 / 2}\right)$ of the polymers are in the voltage range of 0.76 to $0.83 \mathrm{~V}$, depending on the polymer composition. This demonstrates that the ferrocene units in the PACTs have similar redox behaviors due to the lack of electronic interaction between the ferrocene and the formed aroxycarbonyltriazole units. ${ }^{5,12}$

Ferrocene-based polymers are promising precursors to advanced ceramic materials. Pyrolysis of P3a, P3b and P3c in tube furnaces at $1000{ }^{\circ} \mathrm{C}$ for $1 \mathrm{~h}$ under a stream of nitrogen gave ceramic products C3a, C3b and C3c in 35.4, 19.9 and 29.1\% yields, respectively. All the ceramics are magnetizable and can be readily attracted by using a bar magnet, which prompted us to investigate their magnetic properties and chemical structures.

Their magnetic properties were investigated using a vibrating sample magnetometer. The magnetization curves of the ceramics are given in Fig. 3. With an increase in the magnetic field strength, the magnetization of C3a, C3b and C3c swiftly increased and ultimately reached saturation states of $\sim 27,55$ and 39 emu $^{-1}$, respectively. The stronger saturation magnetization of $\mathbf{C} 3 \mathbf{b}$ may be due to its higher metallic species content. It is worth noting that the value is higher than those of the magnetic nanoparticles fabricated from ferrocene-functionalized disubstituted polyacetylenes $\left(\sim 17-29 \mathrm{emu} \mathrm{g}^{-1}\right),{ }^{13}$ and the complex of a linear poly(ferrocenylsilane) and $\mathrm{Co}_{2}(\mathrm{CO})_{8}$ ( 20-35 emu $\left.\mathrm{g}^{-1}\right) \cdot{ }^{\mathbf{1 4}}$ Additionally, the hysteresis loops of the ceramics are small. As can be seen from the enlarged $H-M$ plots in the inset of Fig. 3, the coercivities of the ceramics are found to be in the range of 0.09-0.23 kOe, indicative of soft magnetism.

The structures of C3a, C3b and C3c were studied by TEM analysis. As can be seen from Fig. S11 (ESI $\dagger$ ), the ceramics are comprised of irregular iron nanoparticles (dark grains) dispersed in the abundant carbon matrix (light areas). Fe is known to catalyze the formation of carbon nanotubes. ${ }^{15}$ From

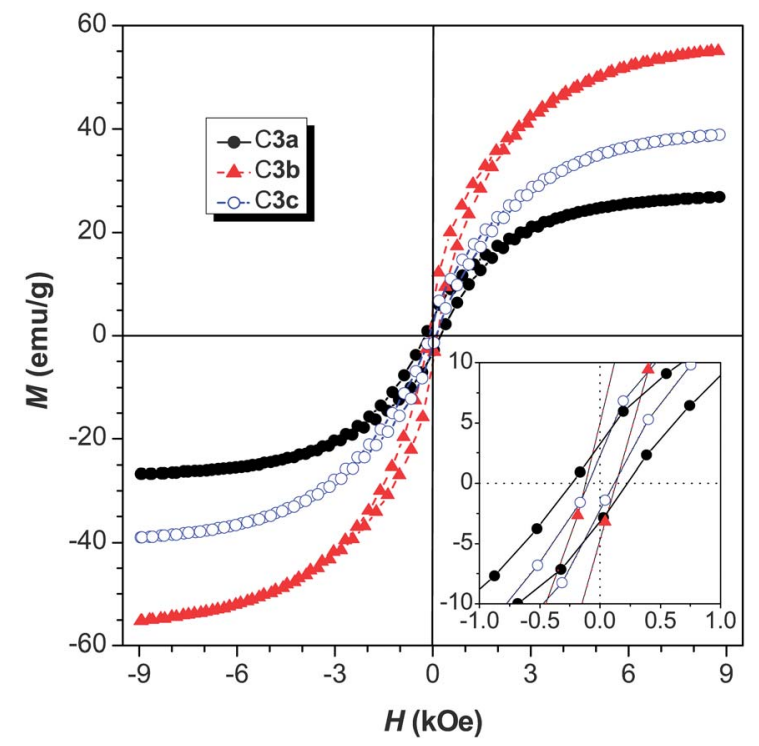

Fig. 3 Plots of magnetization $(M)$ versus applied magnetic field $(H)$ at $298 \mathrm{~K}$ for ceramics C3a, C3b and C3c prepared by pyrolysis at $1000{ }^{\circ} \mathrm{C}$ for $1 \mathrm{~h}$ under nitrogen. Inset: enlarged plots at low magnetic field. 
the TEM images, the Fe nanoparticles are wrapped by a carbonous shell with nanotube structures, which may protect the materials from oxidation.

We then carried out X-ray photoelectron spectroscopy (XPS) analysis to estimate the chemical compositions of the ceramics. The XPS results reveal the iron contents of 5.21, 7.80 and $6.58 \%$ on the surfaces of C3a, C3b and C3c, respectively (Table S2, ESI $\dagger$ ). Furthermore, the XPS study can provide information on the chemical structures of the surfaces of the ceramics. Fig. 4 shows the magnified $\mathrm{Fe} 2 p$ photoelectron spectra of C3a, C3b and C3c. Four peaks are observed at 724, 720, 711 and $707 \mathrm{eV}$. The peaks at 724 and $711 \mathrm{eV}$ are associated with the $\mathrm{Fe} 2 p 1 / 2$ and Fe $2 p 3 / 2$ corelevel binding energies of $\mathrm{Fe}_{2} \mathrm{O}_{3}$, respectively, according to the report that the binding energies of $\mathrm{Fe}$ metal are at 720 and $707 \mathrm{eV} .{ }^{\mathbf{1 6}}$ The emergence of such peaks indicates the presence of iron oxide and metallic iron on the surfaces of the ceramics.

In order to obtain more insight into the chemical structures of the ceramics, we performed powder X-ray diffraction (XRD) analysis. From the XRD patterns of C3a, C3b and C3c shown in Fig. S12 (ESI $\dagger$ ), we can see that all the ceramics exhibit Bragg reflection at $2 \theta$ angles of 43.8 and 44.7 , demonstrating that they all contain crystalline species. The reflection peaks can be identified according to the databases of JCPDS-International Centre for Diffraction Data (ICDD) as reflections for the iron metal of $\mathrm{Fe}_{3} \mathrm{C}$ and $\mathrm{Fe}$ (ICDD data file 23-1113 and 06-0696, respectively).

In summary, a group of ferrocene-based PACTs were prepared by our established propiolate-azide metal-free click polymerization. The reactions of dipropiolates $\mathbf{1}$ and diazide $\mathbf{2}$ were carried out in DMF at $80{ }^{\circ} \mathrm{C}$ for $24 \mathrm{~h}$, and soluble P3 with high molecular weights and regioregularities were obtained in high yields. Furthermore, these polymerization reactions could proceed smoothly in the open atmosphere, and oxygen and moisture were not needed to be excluded. The resultant PACTs are thermally stable and redox active. The pyrolysis of these

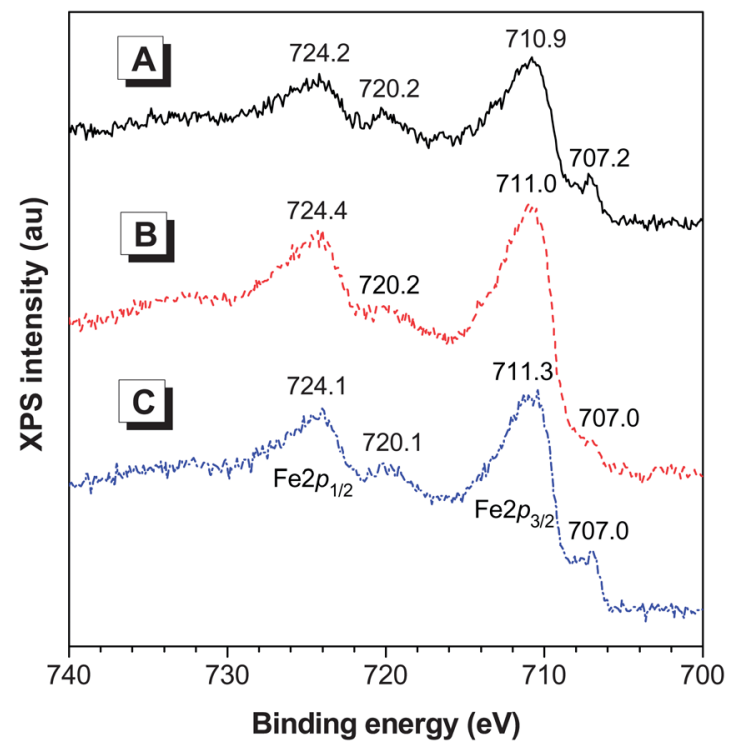

Fig. 4 Fe2p photoelectron spectra of (A) C3a, (B) C3b and (C) C3c. polymers readily generates ceramics with high magnetizability and low coercivity, which enable them to serve as polymer precursors to soft magnetic materials. Other functionalization and applications of these polymers are under investigation in our group.

\section{Acknowledgements}

This work was partially supported by the National Science Foundation of China (21222402, 21174120, and 20974098); the key project of the Ministry of Science and Technology of China (2013CB834702 and 2009CB623605), and the Research Grants Council of Hong Kong (604913, 604711 and HKUST2/CRF/10).

\section{Notes and references}

1 (a) A. S. Abd-El-Aziz, P. O. Shipman, B. N. Boden and W. S. McNeil, Prog. Polym. Sci., 2010, 35, 714; (b) K. A. Williams, A. J. Boydston and C. W. Bielawski, Chem. Soc. Rev., 2007, 36, 729; (c) C. K. A. Gregson, V. C. Gibson, N. J. Long, E. L. Marshall, P. J. Oxford and A. J. P. White, J. Am. Chem. Soc., 2006, 128, 7410; (d) G. R. Newkome, E. He and C. N. Moorefield, Chem. Rev., 1999, 99, 1689.

2 (a) P. Nguyen, P. Gomez-Elipe and I. Manners, Chem. Rev., 1999, 99, 1515; (b) R. D. A. Hudson, J. Organomet. Chem., 2001, 637-639, 47; (c) M. Kurihara, A. Hirooka and S. Kume, J. Am. Chem. Soc., 2002, 124, 8800; (d) V. C. Gibson, N. J. Long and P. J. Oxford, Organometallics, 2006, 25, 1932; (e) M. Häussler, J. W. Y. Lam, R. Zheng, H. Dong, H. Tong and B. Z. Tang, J. Inorg. Organomet. Polym. Mater., 2005, 15, 519.

3 (a) P. F. Brandt and T. B. Rauchfuss, J. Am. Chem. Soc., 1992, 114, 1926; (b) M. R. Buchmeiser, N. Schuler, G. Kaltenhauser, K. H. Ongania, I. Lagoja, K. Wurst and H. Schottenberger, Macromolecules, 1998, 31, 3175; (c) A. S. Abd-El-Aziz, T. H. Afifi, W. R. Budakowski, K. J. Friesen and E. K. Todd, Macromolecules, 2002, 35, 8929; (d) C. Lang, D. Voll, A. J. Inglis, N. Dingenouts, A. S. Goldmann, L. Barner and C. Barner-Kowollik, Macromol. Chem. Phys., 2011, 212, 831; (e) C. K. W. Jim, A. Qin, J. W. Y. Lam, M. Häussler and B. Z. Tang, J. Inorg. Organomet. Polym. Mater., 2007, 17, 289; (f) W. A. Amer, L. Wang, A. M. Amin, L. Ma and H. J. Yu, J. Inorg. Organomet. Polym. Mater., 2010, $20,605$.

4 (a) D. A. Foucher, B. Z. Tang and I. Manners, J. Am. Chem. Soc., 1992, 114, 6246; (b) D. A. Foucher, R. Ziembinski, B. Z. Tang, P. M. MacDonald, J. Massey, C. R. Jaeger, G. J. Vancso and I. Manners, Macromolecules, 1993, 26, 2878; (c) I. Manners, Science, 2001, 294, 1664.

5 (a) Q. Sun, J. W. Y. Lam, K. Xu and B. Z. Tang, Chem. Mater., 2000, 12, 2617; (b) Z. Li, J. W. Y. Lam, Y. Q. Dong, Y. P. Dong, H. H. Y. Sung, I. D. Williams and B. Z. Tang, Macromolecules, 2006, 39, 6458; (c) M. Häussler, A. Qin and B. Z. Tang, Polymer, 2007, 48, 6181; (d) J. Shi, C. K. W. Jim, F. Mahtab, J. Liu, J. W. Y. Lam, H. H. Y. Sung, I. D. Williams, Y. Dong and B. Z. Tang, Macromolecules, 2010, 43, 680; (e) C. K. W. Jim, J. W. Y. Lam, A. Qin, C. W. T. Leung, J. Liu, 
H. H. Y. Sung, I. D. Williams and B. Z. Tang, J. Inorg. Organomet. Polym. Mater., 2013, 23, 147.

6 (a) A. J. Qin, J. W. Y. Lam and B. Z. Tang, Chem. Soc. Rev., 2010, 39, 2522; (b) A. J. Qin, J. W. Y. Lam and B. Z. Tang, Macromolecules, 2010, 43, 8693; (c) H. K. Li, A. J. Qin, J. Z. Sun and B. Z. Tang, Chin. J. Polym. Sci., 2012, 30, 1; (d) B. S. Sumerlin and A. P. Vogt, Macromolecules, 2010, 43, 1; (e) W. H. Binder and R. Sachsenhofer, Macromol. Rapid Commun., 2007, 28, 15.

7 (a) V. V. Rostovtsev, L. G. Green, V. V. Fokin and K. B. Sharpless, Angew. Chem., Int. Ed., 2002, 41, 2596; (b) C. W. Tornøe, C. Christensen and M. Meldal, J. Org. Chem., 2002, 67, 3057; (c) C. N. Lo and C. S. Hsu, J. Polym. Sci., Part A: Polym. Chem., 2011, 49, 3355; (d) J. S. Park, Y. H. Kim, M. Song, C. H. Kim, Md. A. Karim, J. W. Lee, Y. S. Gal, P. Kumar, S. W. Kang and S. H. Jin, Macromol. Chem. Phys., 2011, 211, 2464; (e) Y. L. Angell and K. Burgess, Chem. Soc. Rev., 2007, 36, 1674; (f) J. F. Lutz and H. G. Börner, Prog. Polym. Sci., 2008, 33, 1; $(g)$ M. Meldal and C. W. Tornøe, Chem. Rev., 2008, 108, 2952; (h) F. Amblard, J. H. Cho and R. F. Schinazi, Chem. Rev., 2009, 109, 4207; (i) J. E. Hein and V. V. Fokin, Chem. Soc. Rev., 2010, 39, 1302; (j) C. Chu and R. Liu, Chem. Soc. Rev., 2011, 40, 2177; (k) R. Fu and G. D. Fu, Polym. Chem., 2011, 2, 465; (l) G. Wang, J. L. Geng, X. H. Zhang, L. P. Cai, D. Ding, K. Li, L. Wang, Y. H. Lai and B. Liu, Polym. Chem., 2012, 3, 2464.

8 (a) J. C. Swarts, E. W. Neuse and G. J. Lamprecht, J. Inorg. Organomet. Polym. Mater., 1994, 4, 143; (b) Macromolecules Containing Metal and Metal-Like Elements, Biomedical Applications, ed. A. S. Abd-El-Aziz, C. E. Carraher, C. U. Pittman, J. E. Sheats and M. Zeldin, John Wiley \& Sons, 2004 , ch. 1.
9 (a) J. Liu, J. W. Y. Lam and B. Z. Tang, Chem. Rev., 2009, 109, 5799; (b) A. J. Qin, J. W. Y. Lam and B. Z. Tang, Prog. Polym. Sci., 2012, 37, 182; (c) R. Hu, J. W. Y. Lam and B. Z. Tang, Macromol. Chem. Phys., 2013, 214, 175.

10 (a) Q. Wei, J. Wang, X. Shen, X. Zhang, J. Z. Sun, A. Qin and B. Z. Tang, Sci. Rep., 2013, 3, 1093; (b) A. J. Qin, L. Tang, J. W. Y. Lam, C. K. W. Jim, Y. Yu, H. Zhao, J. Z. Sun and B. Z. Tang, Adv. Funct. Mater., 2009, 19, 1891; (c) A. J. Qin, C. K. W. Jim, W. X. Lu, J. W. Y. Lam, M. Häussler, Y. Q. Dong, H. H. Y. Sung, I. D. Williams, G. K. L. Wong and B. Z. Tang, Macromolecules, 2007, 40, 2308; (d) H. Li, J. Mei, J. Wang, S. Zhang, Q. Zhao, Q. Wei, A. J. Qin, J. Z. Sun and B. Z. Tang, Sci. China: Chem., 2011, 54, 611; (e) H. Li, J. Wang, J. Z. Sun, R. Hu, A. J. Qin and B. Z. Tang, Polym. Chem., 2012, 3, 1075; (f) Q. Wang, H. Li, Q. Wei, J. Z. Sun, J. Wang, X. Zhang, A. Qin and B. Z. Tang, Polym. Chem., 2013, 4, 1396.

11 H. C. Kolb, M. G. Finn and K. B. Sharpless, Angew. Chem., Int. Ed., 2001, 40, 2004.

12 A. Labande, J. Ruiz and D. Astruc, J. Am. Chem. Soc., 2002, 124, 1782.

13 C. K. W. Jim, A. Qin, F. Mahtab, J. W. Y. Lam and B. Z. Tang, Chem.-Asian J., 2011, 6, 2753.

14 A. Berenbaum, M. Ginzburg-Margau, N. Coombs, A. J. Lough, A. Safa-Sefat, J. E. Greedan, G. A. Ozin and I. Manners, Adv. Mater., 2003, 15, 51.

15 (a) K. Hernadi, A. Fonseca, J. B. Nagy, D. Bernaerts and A. A. Lucas, Carbon, 1996, 34, 1249; (b) K. Kuwana and K. Saito, Carbon, 2005, 43, 2089.

16 (a) G. Allen, M. Curtis, A. J. Hopper and P. M. Tucker, J. Chem. Soc., Dalton Trans., 1974, 14, 1525; (b) C. S. Fradley, in Electron Spectroscopy, ed. D. A. Shirley, North-Holland, Amsterdam, 1972, pp. 781. 